\title{
Accelerate innovation towards sustainable living: exploring the potential of Living Labs in a recently completed case
}

\author{
Sofie Andersson* and Ulrike Rahe \\ Department of Industrial and Materials Science, \\ Division Design \& Human Factors, \\ Chalmers University of Technology, \\ SE-412 96 Gothenburg, Sweden \\ Email: sofiean@chalmers.se \\ Email: ulrike.rahe@chalmers.se \\ *Corresponding author
}

\begin{abstract}
The built environment accounts for over one-third of both global final energy use and $\mathrm{CO}_{2}$ emissions. This sector is, however, particularly prone to 'lock-in' with many strong barriers hindering the market uptake of sustainable innovations. Additionally, various studies have shown that user behaviour may outweigh efficiency improvements achieved through technological innovations in buildings. The emerging area of Living Labs has been proposed as a means to accelerate the development of innovations in the building sector. This paper elaborates on challenges for sustainable living from a wide perspective and explores the potential of Living Labs to address some of these challenges in order to accelerate innovation. The research environment for the study is a newly built Living Lab located in the south-west region of Sweden.
\end{abstract}

Keywords: sustainable living; Living Labs; innovation acceleration; demonstrator; co-creation; change process; residential buildings; sustainability challenges.

Reference to this paper should be made as follows: Andersson, S. and Rahe, U. (2017) 'Accelerate innovation towards sustainable living: exploring the potential of Living Labs in a recently completed case', J. Design Research, Vol. 15, Nos. 3/4, pp.234-257.

Biographical notes: Sofie Andersson is a Research Engineer at Chalmers University of Technology, Division Design \& Human Factors. She is currently involved in the project More by Less, which aims to study how products and services in a future smart energy grid can enable residents to use energy in a more sustainable way while maintaining their quality of life. She holds a MS in Industrial Design Engineering from the Chalmers University of Technology.

Ulrike Rahe is a Professor in Industrial Design at Chalmers, Division Design \& Human Factors since 2003. In her cross-disciplinary research in the intersection between design, sustainability and wellbeing, she investigates and promotes opportunities for a more likable and sustainable future, focusing on user behaviour, needs and wishes in daily life. Beside her academic work, she has always been working as a consultant for industry, driving design-innovations that both encourage reduced consumption of resources 
and energy simultaneously as the individual's quality of life and general satisfaction to be improved. As a highly renowned designer, she has won over 50 international design awards shown in more than 50 international exhibitions.

\section{Introduction}

The worldwide consumption of natural resources is still rising beyond our planet's natural boundaries, triggering effects such as climate change, environmental pollution and degradation of ecosystems (Rockström et al., 2009; Bringezu and Bleischwitz, 2009). Further challenges arise from demographic changes with an ageing population (United Nations, 2015a), a decrease in average household size (Eurostat, 2016) and continued urbanisation (United Nations, 2015b). The built environment plays a central role in these challenges as it accounts for over one-third of global final energy use as well as $\mathrm{CO}_{2}$ emissions (International Energy Agency, 2013). The building sector is, however, slow to integrate new technology and innovate (Rosado et al., 2014; Pinkse and Dommisse, 2009; International Energy Agency, 2013). In its current state, it will not be able to meet the societal needs for housing while also keeping up with the global need for reduced resource use (Rosado et al., 2014).

Examples of buildings that to a large extent utilise 'green technologies' and have a near zero net energy consumption only represent a small niche within today's market and existing building stock (International Energy Agency, 2013). Strong barriers exist in the building industry that hinder the market uptake of sustainable innovations, which may be considered particularly risky as they often require contractors to break loose from established technologies that have become 'locked-in' (Pinkse and Dommisse, 2009). Additionally, energy savings obtained during the use-phase of buildings from the introduction of sustainable innovations may neither lead to a competitive advantage nor generate direct returns on investment (Beerepoot and Beerepoot, 2007). The complex nature of the building industry with individual projects that are often of a unique character, dominated by stakeholder negotiations, price competition and the risk of market failure, makes it difficult to be flexible in the implementation of emerging technologies (Beerepoot and Beerepoot, 2007). Because of the difficulty of providing space for a longer-term knowledge-exchange, strong collaborations between different stakeholders are hindered (Beerepoot and Beerepoot, 2007).

Being some of the longest-lived components of society, buildings will have an impact on energy use and emissions for many decades after being constructed or retrofitted, which makes the building sector particularly prone to lock-in (Lucon et al., 2014). According to Beerepoot and Beerepoot (2007), the building industry is characterised by incremental changes that are applied to comply with new standards and regulations from the Government, which have not been forceful enough to contribute to the diffusion of radical or really new innovations. It has, furthermore, emerged in various studies that what are termed 'green buildings' consume more energy in reality than predicted by the energy label (Majcen et al., 2013). Lifestyle factors are being acknowledged as some of the most challenging barriers to resource consumption reduction today (Kalmykova et al., 2016). 
However, efforts to reduce residential use of energy have mainly focused on the development of more efficient technologies and buildings, while the actual use of these has been the subject of significantly less interest (Gram-Hanssen, 2013; Janda, 2011; Guerra-Santin, 2017). Efficiency improvements may either be outweighed by an overall increase in appliances and living space (Gram-Hanssen, 2013) or by changed behavioural patterns such as increased use, commonly referred to as the rebound effect (Hertwich, 2005; Liedtke et al., 2012; Guerra-Santin, 2017; Buhl, 2014).

Rosado et al. (2014) propose that innovation in the building sector can be accelerated via what is called 'open innovation', which is a process where external actors are included in collaboration to create opportunities to introduce ideas and products to the market at a quicker pace. The concept of Living Labs provides a co-creative platform for transdisciplinary research and experimentation that aims to promote open innovation (Rosado et al., 2014). Due to the clearly delimited space of a Living Lab concept, it offers a small scale platform, enabling residents as well as other stakeholders to become engaged and get actively involved. The approach shows great promise for developing innovative solutions for future sustainable living (Liedtke et al., 2012).

This paper presents an exploratory study carried out in a newly completed Living Lab, located in the south-west region of Sweden, hereafter referred to as the Case Living $L a b$. It elaborates on challenges for sustainable living from a wide perspective as discussed by different stakeholders involved in the Case Living Lab project and explores the potential of Living Labs to address these issues to accelerate innovations towards sustainable living. The paper focuses on how to make best use of a Living Lab facility and it therefore has relevance to anyone planning to perform or participate in a Living Lab project focused on sustainable living but also to participants of other multidisciplinary collaboration projects in the building sector.

\section{Living Lab research}

\subsection{The Case Living Lab}

The Case Living Lab of this study was completed in June 2016 and is today also home to 33 residents, in addition to being a research and demonstration area. The building is equipped with 2,000 sensors measuring, for example, electricity, heating and water flows as well as the indoor climate, the location of residents inside the building and the weather conditions outside the building. The collected data will be used to support various research projects taking place in the Living Lab. Being constructed in prefabricated modules with exchangeable façade elements, the Case Living Lab offers flexibility for major changes to be made to the living space and experimentation with different materials in relation to outdoor weather conditions as well as indoor climate, besides all user behaviour-related research connected to the daily practices of living.

The Case Living Lab is a four-storey building, containing 29 dwellings, of which five are private apartments in varying sizes and layouts. The remaining 24 dwellings are organised in the form of shared communities, called 'clusters' here, instead. They consist of private rooms measuring 13 square metres, or more accurately cubes, with dimensions of $3.6 \times 3.6 \times 3.6 \mathrm{~m}$, distributed in four architecturally identical clusters. The six residents in each cluster share a spacious common area containing two sets of fully 
equipped kitchens, two bathrooms with a storage loft above, and a living area section for socialising. The private rooms contain a small kitchen section without an oven or hob, a small bathroom without a shower, a sleeping loft and an open storage system. Figure 1 shows a floor plan drawing of a cluster in the Case Living Lab.

The Case Living Lab project was initiated collectively by a technical university, the largest housing company in Sweden and a local science park. In this paper they will be referred to as the three core partners of the project. Once initiated, the core partners started to build up a business eco-system around the Case Living Lab by recruiting ten additional partners from different sectors related to housing and the built environment, in this paper referred to as business partners. In this way, the Case Living Lab gathers different stakeholders around one table and creates a 'free zone' for discussions and experimentations that cannot normally take place.

One of the main purposes of the Case Living Lab is to challenge the idea of what a home is and explore new ways of enabling more sustainable living. It is referred to by the research team as the first ever 3rd generation Living Lab, meaning that it is a research platform that aims to optimise the interface between systems and users in a real-life setting. Table 1 shows an overview of the different generations of Living Labs, as suggested by the Case Living Lab project team.

Figure 1 Layout of a cluster with six single cubes in the Case Living Lab

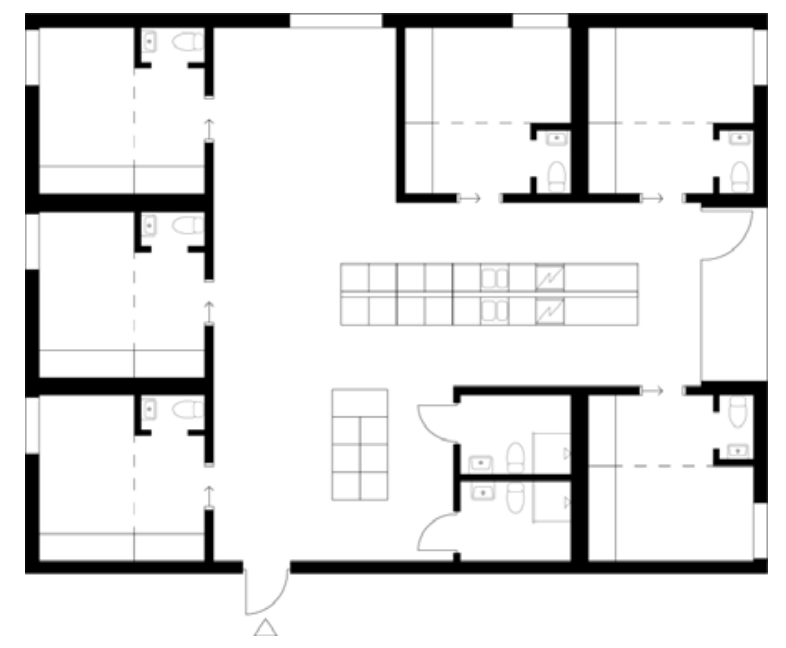

Table 1 Generations of Living Labs, as suggested by the Case Living Lab project team

\begin{tabular}{|c|c|c|c|}
\hline Generation zero & 1st generation & 2nd generation & $3 r d$ generation \\
\hline $\begin{array}{l}\text { The need to assess } \\
\text { the performance of a } \\
\text { single technology }\end{array}$ & $\begin{array}{c}\text { The need to assess } \\
\text { the performance of a } \\
\text { system }\end{array}$ & $\begin{array}{c}\text { The need to assess } \\
\text { the performance of a } \\
\text { single technology and } \\
\text { a user }\end{array}$ & $\begin{array}{c}\text { The need to optimise } \\
\text { the interface between } \\
\text { human behaviour and } \\
\text { systems }\end{array}$ \\
\hline \multirow[t]{2}{*}{$\begin{array}{l}\text { Normalised tests and } \\
\text { standards }\end{array}$} & $\begin{array}{c}\text { Unoccupied } \\
\text { demonstrators }\end{array}$ & $\begin{array}{c}\text { Occupied } \\
\text { demonstrators }\end{array}$ & $\begin{array}{l}\text { Co-creation } \\
\text { environment }\end{array}$ \\
\hline & & & $\begin{array}{l}\text { Modular and flexible } \\
\text { spaces }\end{array}$ \\
\hline
\end{tabular}




\title{
2.2 Contribution of the Case Living Lab to the Living Lab concept
}

The concept of Living Labs was originally developed at the Massachusetts Institute of Technology (MIT) in Boston (Pierson and Lievens, 2005). A Living Lab for Sustainable Development is defined by Geibler et al. (2014) as:

\begin{abstract}
“...a research approach aimed at open socio-technical innovation processes, in which users as well as relevant actors of the value chain and the utilisation environment participate in the development and application of new products, services and system solutions. The interactive innovation process takes place in the real environment of the users (e.g., user observation, field tests) and/or in laboratories that are configured for user interactions (e.g., for the development of prototypes). The innovation process is guided by sustainability criteria and aims to contribute to production and consumption patterns that can be applied on the global and long-term scale and are inter- and intragenerationally viable."
\end{abstract}

This definition is a valid means of describing the nature of the Case Living Lab presented in this paper but we would, however, like to add the following sentences to supplement the definition:

"A sustainability Living Lab aims at challenging norms and providing a platform for new and extended collaboration where actors and users can jointly explore new ways of enabling sustainable living with few risks and restrictions. The goal is to develop innovations that, apart from improving environmental sustainability and being economically viable, may also have positive effects on wellbeing."

\subsection{The Living Lab approach}

A process where you enter a real-world situation with the aim of acquiring knowledge as well as improving it is termed action research (Baskerville and Wood-Harper, 1998; Checkland and Holwell, 1998), which Bergvall-Kåreborn and Ståhlbröst (2009) suggest as being a suitable method for the research carried out in Living Labs. Living Labs focused on sustainable living may also apply social practice theory to conceptualise daily routines and their transformation into more sustainable patterns (Hasselkuß et al., 2017). Social practice theory describes everyday doings as elements that "shape individuals" perceptions, interpretations and actions within the world" (Hargreaves, 2011).

A strategy for performing Living Lab research that aims to facilitate user involvement while connecting academia, industry and society is the Three-tier model described by Keyson et al. (2017). The Three-tier model consists of three steps:

1 insight studies into current practices in existing homes

2 studies in Living Labs equipped with innovative products and services focused on sustainable living

3 field testing, in which innovative sustainable technologies developed from the Living Lab research are scaled up through implementation in existing homes (Keyson et al., 2017).

The Three-tier model will to a large extent also be applied in the Case Living Lab, where several projects originated in insight studies performed earlier with the aim of being scaled up and tested in a wider range of buildings and homes after the Living Lab test phase. 


\subsection{Living Lab actors}

Leminen et al. (2012) differentiate between four types of Living Labs based on the kind of actor that drives the Living Lab activities. These are utilisers, enablers, providers and users. Based on this classification, Schuurman et al. (2016) proposed five different roles for actors involved in Living Labs by also adding the role of researchers, who in the original definition by Leminen et al. (2012) belong to the group of providers by being part of a technical university. As defined by Schuurman et al. (2016), utilisers are often involved in short-term projects and use Living Labs as a strategic tool to develop and test their products or services in collaboration with users and other stakeholders. Enablers support and facilitate the Living Lab project by providing financial resources or policy support for the different operations in the Living Lab. Providers, like utilisers, are involved in the co-development of new products and services, but are more focused on long-term results and their role is, better suited to larger companies with more established technologies according to Schuurman et al. (2016). Users can be referred to as the endusers of Living Labs and the technologies included in them. Researchers may be involved in user research as well as topics related to technology, business or policy (Schuurman et al., 2016).

When comparing the study participants with the actor classification suggested by Schuurman et al. (2016), all five roles are covered in the Case Living Lab partner structure. According to Bergvall-Kåreborn and Ståhlbröst (2009), it is important to have a mixture of large, medium and small organisations in the Living Lab partnership since they have different experiences and resources and may therefore introduce different opportunities. Bergvall-Kåreborn and Ståhlbröst (2009) also recommend mixing both long and short-term partnerships, as the stable partnerships give continuity to the Living Lab project while the more flexible partnerships contribute new perspectives and ideas.

\subsection{Living Lab success factors and barriers}

Living Labs offer possibilities for experimentation in innovative projects at a relatively low cost (Nesti, 2017). Due to a lack of funding, political support and long-term planning, Living Labs are, however, subject to a high mortality rate (Nesti, 2017).

Geibler et al. (2014) identified several barriers to a Sustainability Living Lab approach. Some were related to a narrow interest and focus on specific products and technologies, which may prevent the implementation of sustainable innovations of a service-oriented nature or on a systemic scale (Geibler et al., 2014). The success of a Living Lab in achieving sustainable innovations may furthermore be hindered by a low visibility preventing a broader spread of its outcomes and by rivalry in the research and development field, which may hinder open innovation processes (Geibler et al., 2014).

Schuurman et al. (2016) stress the importance of allowing activities to take place from an early stage in a completed Living Lab, not only to confirm the operation of the consortium but also to engage the users and attract external actors. This demands early definition of use cases to actually get the Living Lab running (Schuurman et al., 2016). Geibler et al. (2014) concluded that a key condition for a successful Sustainability Living $\mathrm{Lab}$ infrastructure is a long time horizon. This can be related to one of the key principles for Living Lab operations suggested by CoreLabs (2007), which is continuity. They argue that creativity is strengthened by strong cross-border collaborations that build on trust and 
this takes time to achieve. Despite this, Geibler et al. (2014) found that many existing Living Labs are only used for fixed-term projects.

A second key principle is openness, which is important in order to gather a wide range of perspectives as well as enough power to achieve rapid progress (CoreLabs, 2007). Realism is necessary to generate results that are valid for real markets while empowerment of users is fundamental in order to base the innovation process on user needs and desires (CoreLabs, 2007). CoreLabs (2007) argue that users should be engaged not only in single projects but over time in various innovation processes, in order to gain experience and thereby become more effective as innovators. The final key principle they suggest is spontaneity, stressing the importance of inspiring usage and having the ability to detect spontaneous user reactions.

Out of the five principles presented above, Bergvall-Kåreborn and Ståhlbröst (2009) identify three that represent the core of Living Labs:

1 empowerment of users

2 openness

3 realism.

They conclude that realism is the one principle that is the most difficult to achieve, due to a lack of knowledge and experience of true interaction in the real-world environment of the users throughout the whole development process. They argue that more knowledge should be gathered in this area, as this principle is what distinguishes Living Labs from other open and user-centred approaches.

The importance of studying everyday activities as the approach towards resource use reduction (Selvefors, 2017) can be seen as a strong argument for the realism in the Case Living Lab setting. The relevance of exploring peoples' daily behaviour and their conflicts in everyday life with competing goals could not be investigated in a temporary or rigged setting (Selvefors et al., 2015). The Case Living Lab as the 3rd Generation Living Lab is particularly suitable for that, since it constitutes a permanent home and thus the natural everyday environment of its residents.

\section{Research approach and methodology}

\subsection{Research aim}

The research aim of this paper is to investigate how to best utilise a Living Lab facility as an accelerator for sustainable living innovations. The research questions are: What challenges for sustainable living should a Living Lab project focus its efforts on? How should a Living Lab be designed and utilised in order to enable exploration of new settings for sustainable living? What roles do different actors have in terms of keeping the Living Lab alive and in making sure that ideas developed in the Living Lab reach a wider market?

The research in this paper builds on previous Living Lab research as well as open innovation research. The wide focus on sustainability challenges from the perspectives of different Living Lab actors aims to take a step back and consider what we really want to 
achieve with the concept of Sustainability Living Labs and in which direction we want new innovations to take us.

\subsection{Procedure and participants}

The empirical basis for this paper is an exploratory study including a series of interviews, focus groups as well as an online survey collecting both qualitative and quantitative data. Therefore, a mixed methods approach, as described by Creswell and Clark (2011) and Johnson and Onwuegbuzie (2004) has been adopted to facilitate interpretation and comparison of the data. The participants included in the study were both residents and other actors in the Case Living Lab project. In this way, perspectives from two groups that have a completely different relationship to the Living Lab were considered in the study.

\subsubsection{Interviews}

A total of 22 semi-structured interviews were performed with stakeholders in the Living Lab project, with the aim of clarifying their roles and objectives in the project as well as taking note of their thoughts on the topic of future sustainable living. The interviews were conducted between four and six months after the Living Lab building was finished. The participants were recruited via email or phone call and were given the option of selecting whether they preferred to have the interview over the phone/skype or to meet in person, in which case they were also free to choose the venue for the interview. All except two of the stakeholders approached agreed to participate. Thirteen of the interviews were held with representatives from the three core partners and eight interviews were held with representatives from business partners. Finally, one interview was held with a journalist with great insight into and knowledge of the project.

The interviews followed a pre-determined question structure, allowing for follow-up questions whenever needed. Some of the core questions asked were:

- What potential do you see in this project?

- How will you use the results from the data collected?

- What are your ideas for future research in the Living Lab?

- What do you think will be the biggest challenges in providing sustainable homes in the future?

The interviews lasted for around 30 minutes and were in most cases audio-recorded, with the agreement of the participants, except for a few interviews that were held via phone or Skype where the content was recorded by taking notes instead. The interviews were held in either Swedish or English, depending on the language preference of the interviewees.

\subsubsection{Focus groups}

Focus groups were held with residents about three months after their move to the Living Lab. This method was selected as an efficient way of bringing several residents together to share their experiences about the Living Lab and to enable a group discussion. A total of 16 residents, which corresponds to almost half of the tenants, participated in four 
different focus group sessions. These were held in a conference room on the entrance floor of the Living Lab building, to make it as convenient as possible for the participants. Examples of the topics discussed were the reasons for moving there, the residents' expectations and how they would like to take part in any further development of the Living Lab. The participants shared experiences of their living space and discussed the distribution between private and common spaces in the clusters. The participants were also asked about their thoughts concerning sustainability, the use of resources and technology.

The focus group participants represented all four clusters as well as three of the five apartments in the Living Lab. The sessions used a total time span of around two hours each. The first part of each session was, however, dedicated to a different study to the one presented in this paper. All focus groups were recorded both in video and audio, with the agreement of the participants. Depending on the nationalities of the participants, the focus groups were held in either Swedish or English.

\subsubsection{Online survey}

An online survey was sent out to all the residents in the Living Lab via email a couple of weeks after the first focus groups had been held. This method was selected as an efficient way of reaching as many of the residents as possible, and of collecting quantitative data to complement the qualitative data from the focus groups. To promote participation, a flyer with information about the survey and the projects behind it was distributed in the residents' post boxes beforehand. Additionally, all residents who completed the survey were given cinema tickets to thank them for their participation. Of the 33 residents in the Living Lab, 25 responded to the online survey, giving a response rate of approximately $76 \%$.

The survey was concerned with similar topics to the ones brought up in the focus groups. It was divided into different sections starting with general information about the respondents, followed by a few sections regarding their use of living space and a few final sections regarding sustainability, future homes and expectations. The survey was in English and the questions were a mix of multiple choice questions, rating scales, rankings and open ended questions. Before being distributed to the Living Lab residents, the survey was pilot tested by a person living in a conventional student apartment. The estimated time required to answer the survey was approximately 20 minutes.

\subsection{Analysis}

Recordings from the interviews and focus groups were transcribed and then imported in digitised form to the software NVivo 11.3.2. Here, the qualitative data was then analysed using an iterative procedure for thematic coding as described by Miles and Huberman (1994). The data was organised by dividing it into smaller segments that were coded into different themes, while at the same time searching for emerging themes and patterns. This finally resulted in a set of main topics with associated subcategories that could subsequently be used as a basis for interpreting the data. Insights about the different topics were summarised in a second document together with quotes to illustrate the contents. The selected quotes, originally in Swedish, were translated into English by the first author. The summarised qualitative data was then compared with quantitative data from the survey. 


\section{Findings}

\subsection{Residents of the Case Living Lab}

An overview of the residents who participated in the study is provided in Table 2.

Table 2 Study participants from the Case Living Lab residents

\begin{tabular}{|c|c|c|c|c|c|}
\hline $\begin{array}{l}\text { Study } \\
\text { participation }\end{array}$ & $\begin{array}{l}\text { Living } \\
\text { Lab role }\end{array}$ & Gender & Age & Occupation & $\begin{array}{l}\text { Type of } \\
\text { dwelling }\end{array}$ \\
\hline \multirow{6}{*}{$\begin{array}{l}25 \text { survey } \\
\text { respondents }\end{array}$} & \multirow[t]{6}{*}{ Users } & $60 \%$ male & $48 \% 18-24$ & $64 \%$ students & \multirow{2}{*}{$\begin{array}{l}72 \% \text { single } \\
\text { room in cluster }\end{array}$} \\
\hline & & \multirow[t]{5}{*}{$40 \%$ female } & $36 \% 25-34$ & $20 \%$ researchers & \\
\hline & & & $8 \% 35-44$ & $16 \%$ other: & \multirow{4}{*}{$\begin{array}{c}28 \% \text { private } \\
\text { apartment }\end{array}$} \\
\hline & & & $4 \% 45-54$ & 'PhD student' & \\
\hline & & & \multirow{2}{*}{$\begin{array}{c}4 \% 55 \text { or } \\
\text { older }\end{array}$} & 'Working in marketing' & \\
\hline & & & & 'Working in hospitality' & \\
\hline \multirow{3}{*}{$\begin{array}{l}16 \text { focus } \\
\text { group } \\
\text { participants }\end{array}$} & \multirow[t]{3}{*}{ Users } & $50 \%$ male & & & \multirow{3}{*}{$\begin{array}{l}69 \% \text { single } \\
\text { room in cluster } \\
31 \% \text { private } \\
\text { apartment }\end{array}$} \\
\hline & & $50 \%$ female & & & \\
\hline & & & & & \\
\hline
\end{tabular}

\subsubsection{Reasons for moving to the Case Living Lab}

It became evident from the focus groups that many residents of the Case Living Lab thought that it was an exciting thing to be part of, both in terms of the research projects going on there as well as the social setting in which they were living: "...it sounded cool to have these social experiments in the building and being a part of the front edge of science in housing". This was confirmed by the survey results showing that the most common reason for moving there was "the excitement of being part of the Living Lab". The second most common reason was "the location on the campus" and the third was "social reasons - to be part of a community". The fact that the building was newly built was the fourth most influential factor and "economic reasons" the least common reason. From the focus groups and the survey comments, it was also evident that some of the residents just needed a place to live and that the Case Living Lab seemed like the best choice at the moment: "I was looking for somewhere to live [...] it's like impossible, but I actually thought it would be quite nice to live together with other people and to take part in these different projects".

$74 \%$ of the survey respondents expected to stay between one and three years in the Living Lab and $22 \%$ expected to stay four to six years. Nobody expected to stay longer than that, and only one respondent (4\%) expected to stay less than one year.

\subsubsection{Attitudes towards sustainability}

The survey result and the focus groups indicated that the residents generally have positive attitudes towards reducing their environmental impact and are open to change, which may help them to adopt more sustainable lifestyles. According to the survey results, most participants are interested in knowing more about energy and think that people should be better educated about energy. Most respondents do care about how electricity and heating 
is produced, but are at the same time not very aware of whether energy in their everyday life comes from sustainable resources or not.

\subsubsection{Attitudes towards technology}

The focus groups revealed a variation in the residents' attitudes and relations to technology. While some had a great interest in new technologies and would like technology to help them to do "....as much as possible of the boring stuff", others were more reluctant to let technology take more and more control over their lives. Discussions revolved around the importance of feeling that you are in control of your surroundings and that sometimes, it is nice to use your own intelligence rather than having a computer telling you what to do. Most of them did not feel the need to acquire the latest available models but did in various ways use technology to a large extent in their everyday lives.

The question 'how important is it for you to be up-to-date with the latest technology?' was also asked in the survey, generating the largest share of answers for 'moderately important' (36\%). 'Important' was selected by $32 \%$, 'very important' by $16 \%$, 'of little importance' by $12 \%$ and 'not at all important' by $4 \%$.

\subsubsection{Interest in Case Living Lab research}

In the focus groups and in the survey the residents showed interest in many different research areas, including for instance smart home technologies, energy, waste handling and sharing of resources. Many were also interested in participating in studies concerning behaviour and social aspects and expressed a willingness to receive more information about their energy use. Some explained that they had expected to get more information about their environmental footprint from the sensor data collected:

"I didn't have much idea of what the research was going to be like but I thought it would be nice to see if you could change your way of life, unconsciously, make different choices. I was expecting a little thing to tell me, today you've used this many gallons of water and this many kW."

\subsection{The Case Living Lab actors}

All three Case Living Lab core partners and all business partners except for two were included in the study, and an overview of these is shown in Table 3. The roles and objectives of the partners included are introduced below.

Table 3 Study participants from the Case Living Lab partners

\begin{tabular}{lccc}
\hline Sector & Partnership & Living Lab roles & Study participation \\
\hline Technical university & Core partner & Researcher & 9 interviews \\
& & Enabler & \\
Science park & Provider \\
Housing & Core partner & Enabler & 2 interviews \\
Architecture & Core partner & Provider & 2 interviews \\
Construction & Business partner & Provider & 1 interview \\
Property & Business partner & Provider & - \\
\hline
\end{tabular}


Table 3 Study participants from the Case Living Lab partners (continued)

\begin{tabular}{lccc}
\hline Sector & Partnership & Living Lab roles & Study participation \\
\hline IT & Business partner & Provider & 1 interview \\
Funding & Business partner & Enabler & 1 interview \\
Appliances & Business partner & Utiliser & 1 interview \\
Engineering & Business partner & Provider & 1 interview \\
Energy & Business partner & Provider & 1 interview \\
Storage & Business partner & Utiliser & - \\
Kitchen and bathroom & Business partner & Utiliser & 1 interview \\
\hline
\end{tabular}

\subsubsection{Roles and objectives}

The three core partners who initiated the project are a technical university, a housing company and a science park that work in a triple helix collaboration between academia, industry and society. Their common objective is to achieve more sustainable ways of living. The roles of the stakeholders from academia who were interviewed range from researchers to providers and enablers of the project, according to the definition by Schuurman et al. (2016). Some of their stated objectives were to have the unique opportunity of working with industry partners, becoming leaders in the emerging area of Living Labs and conducting real world experiments with user involvement in a central position where the research is more visible. The housing company wants to find new methods for building more sustainably and taking an active part in the development of society. In this project, they take on the role of a provider. Their aim is to look into environmental as well as social and economic issues in order to be able to provide decent homes for more people. The role of the science park is to enable the project and facilitate collaboration between the different stakeholders. As a management company, they are responsible for exploring new sources of funding and their main focus is on spreading innovations as well as knowledge about the project.

The business partners who were included in the stakeholder interviews were companies within architecture, property, IT, home appliances, kitchen and bathroom furniture, engineering consultancy, energy and funding. They all described the Living Lab as a place where they could challenge their own thinking by learning from each other and being bolder than in their everyday work. Their roles range across providers, utilisers and enablers of the project.

Through this Living Lab, the architecture company sees the potential to create public interest about sustainable living. They also hope to develop the role of the architect in viewing the building as a process rather than as a finished product. For the property company, the Living Lab is a source of inspiration as well as a platform for learning where they hope to find solutions that may benefit the whole housing sector. The IT company aims to realise and implement tomorrow's technical solutions, starting in the Living Lab. Usually, they work a great deal with systems that cannot be allowed to go wrong, which makes it difficult for them to take bolder steps and therefore they see this as a place where they can dare to do more. The energy company is interested in working on digitisation, smart systems based on user behaviour and the integration and interplay between small scale energy solutions in larger systems. The contribution of the engineering consultancy is to support the research projects by evaluating them and 
providing input from industry. One of their objectives is to test new products and systems, for which they see this Living Lab as a catalyst enabling early evaluation. All of the actors presented above can be seen as providers in this Living Lab project. The role of the construction company, which was not represented in the interviews, seems from other interviews also to be closest to that of the group of providers.

The main objective of the funding organisation is to achieve market uptake for innovations and a quicker European spread of the results. This gives them the role of an enabler. The appliance company is mainly involved in the laundry studio, where they want to investigate how to affect energy and water consumption in the laundry process as well as how to create social laundry spaces that, apart from facilitating the task, also create a pleasant environment that encourages spontaneous meetings between residents. A motivation for the kitchen and bathroom company to join the project was to extend their collaboration with business customers to obtain early insights and have an influence on future solutions. They want to investigate needs and values related to future homes, so that they can develop products accordingly. The role of these two partners therefore seems closest to the category of utilisers. The storage company was not represented in the interviews, but from the description from other actors, its role seems to be closest to that of the group of utilisers as well.

\subsection{Challenges for sustainable living}

Both residents and actors were asked to discuss what they perceived to be the main challenges to achieving sustainable living in the future. The following themes emerged:

1 changing structures and facilitating pathways

2 changing behaviour

3 homes for everyone

4 optimising the use of living space

5 defining sustainability

6 collaboration.

Figure 2 shows a combined overview of the main themes and some related keywords that were brought up, which will be further explained below.

\subsubsection{Changing structures and facilitating pathways}

The slow process of changing old structures was discussed as a major concern and frustration by the residents in one of the focus groups. They discussed the issue that it is not enough for new technologies to just be better from a sustainability perspective, there also needs to be enough public interest and demand for a new technology to be scaled up. In order to change the locked-in structures of today's society, they discussed the principle that people should generally be better educated about sustainability. Some residents pointed out that the information provided in the news is often one-sided, presenting problems and disasters rather than opportunities, but as one of them stated: "you can't scare people to do the right choice, scared people never make the right choice". 
The home-related needs are influenced by transformations in society, as was discussed by some of the actors. With the current trend towards urbanisation, there will be challenges in building housing on limited space close to the city centre. Also, our ways of working have gone through significant changes and will probably continue to do so in the future. However, many old structures remain and these are slow to change. One of the actors with a provider role explained:

\begin{abstract}
"There will be new generations of people who see the world differently[...] We are not an industrial society any more, people don't use their bodies for physical work in the same way today as 50-60 years ago. So we have kind of transformed our society but we have kept our old structures[...] So, I think it's a lot about considering how we live and work, even now but perhaps even more importantly in 10-20 years ahead."
\end{abstract}

\title{
4.3.2 Changing behaviour
}

A common understanding among all stakeholders interviewed was that technological innovations alone will not be able to achieve sustainable living, and that changing our behaviour is crucial in this respect. The following quote comes from one of the actors with an enabler role:
"So we come up with electric windows, automatically dimming lights, we are spending money on making sure we are using the washing machine when the electric tariff is low, when the solar systems are running at full power, but I think that a lot of that work could be done just by good behaviour. It's not that difficult to turn on the washing machine when the sun is shining or to dim the lights when you leave the house. So I think that a lot of these technologies we are spending a lot of money on inventing... are not bringing new [innovation]."

In order to make it possible to change existing structures and behaviours, enablers, researchers as well as providers consider that a change in mindsets and values is crucial. This means challenging our ideas about what it is that makes us happy, our ways of using resources and what we define as a home.

The residents also discussed the difficulty of changing unsustainable behaviours that have become the norm today. In the focus groups, some residents discussed whether the actual reason behind the development of new technologies is that people are generally lazy and always strive towards reducing the effort of performing different tasks. In order for people to start acting more sustainably, it was therefore considered that "...it should be easier to live sustainably than it should be to not live sustainably". One focus group participant explained how she felt forced into a system of consumerism that is difficult to break free from even though she would like to be able to share more rather than individually buying new stuff all the time. She explained that "...sometimes you can almost feel a bit disgusted when you know you spent a lot of money on stuff...”.

\subsubsection{Homes for everyone}

The importance of not only focusing on new building construction but also taking care of the existing building stock was described as a key issue in order to accomplish sustainable living in the future, mainly by the actors with a provider or an enabler role. One of the providers commented that we should also make sure that we do not make huge investments in producing new buildings that we then leave to their fate. A trend that one of the utilisers could see was that rental apartments are often built as cheaply as possible, 
which results in using materials that are less durable than the more expensive options. $\mathrm{He}$ also had the experience that tenants are often less careful with the furnishings compared to home owners. Therefore, he could see a challenge in providing cost effective, yet sustainable and long-lasting homes in the format of rental apartments.

A problematic aspect mentioned in relation to today's society was that we tend to focus our efforts on areas with the greatest chance of success, which may not necessarily be the areas that have the greatest need for change: one of the providers mentioned that "...we have a society today where you choose areas where you can succeed in order to show good examples, rather than taking on areas where change is needed". Another provider stated: "What is the point of building one sustainable building when you build ten new [unsustainable buildings] next time?". Considering the previous quotes, a main objective of the building sector should be to include all parts of society and concentrate on how to build accessible and affordable homes for everyone. Several actors with roles as enablers and providers expressed concern about the risk that new solutions for sustainable living would become too expensive and thus exclusive solutions for only a small part of society. The following quote comes from one of the enablers:

\begin{abstract}
"What I see generally when you talk about sustainable solutions, new technology and all that, is that it will only be for the affluent part of society who can afford it, while the rest have to live in the same trash as they did before. Although after all, it is the affluent part of society that creates the greatest carbon footprint $[\ldots]$ and it is they who will get the better solutions instead of looking at their behaviour and how to change their way of living."
\end{abstract}

\title{
4.3.4 Optimising the use of living space
}

The needs which residents place on their living space change over a lifetime. One of the enablers interviewed pointed out that a common phenomenon today is that households living in large houses continue to do so even after the household size has decreased significantly, such as when children grow up and move away from home, leaving only one or two residents in a house that previously was used by twice the amount of people or more. She pointed out that there are of course several motivations for this but one of them is just to be able to provide room for the children when they come home to visit a few times per year. Variable household sizes as well as changed lifestyles, preferences, conditions, health and events in everyday life create a demand for more adaptable and flexible living space.

In the focus groups, the residents from the clusters discussed their experiences of living in such a small amount of personal space and sharing common areas with others. It turned out that the way they use their living space varies a lot between individuals, but also between the four clusters. While some spend most of their time in the common area and basically use their private room "....as a sleeping chamber", others were "...never actually sitting down in the living room..." or felt that they did "....not have the need to be social at home". Something that was appreciated was that "you can choose yourself how social you want to be". When talking about the future, a few of the residents were open to the possibility of continuing to share parts of their living space in their future homes, but in a different setting with more than just one room as their private space. They also considered that in order to make a small living space functional as a home, there would be a need for better solutions for utilising the 'living volume'. 
It became clear from the focus groups that the living space was a topic that the residents had many thoughts about as well as suggestions for improvements. For instance, they complained about the storage system originally included in their private rooms, which some of them had taken the decision to remove themselves, too low a ceiling height in the sleeping loft and an automatic light in the common area, which in several clusters had been fixed by covering the sensor with tape. One resident expressed frustration about the project partners not taking the residents' ideas on board and not taking faster action to solve reported problems. She said that "...we want to feel that we can actually participate and take action and the things we say will matter...".

\subsubsection{Defining sustainability}

Achieving a common definition of sustainability was perceived as difficult. One of the enablers interviewed argued that there is no clear and common understanding of what sustainability is and what it actually means to live in a sustainable way. According to him, sustainable development can be explained as a change process. What matters is not only the results we achieve but, sometimes even more importantly, the direction we choose. Often, this means avoiding unsustainable development, as it is easier to show what is unsustainable rather than what is actually sustainable.

\subsubsection{Collaboration}

Finally, better collaboration between different market players and new business models were brought up as key issues for achieving better solutions for sustainable living and market impact by providers, enablers as well as researchers. A provider stated that there is a need to create sustainable relations, where different partners are open to each other and help each other find better solutions, rather than keeping secrets and working on different systems that are incompatible with each other.

The way of working together with open innovation in a Living Lab was explained as being new to most of the partners and as one of the providers said: "It sounds so easy but it requires an awful lot of work to dare to trust each other". It was also explained by some providers and enablers that, within the project team, there have been slightly different expectations from one another and on what a Living Lab really means, which has generated challenges in finding a common vision and a common language for all partners. This requires the establishment of a solid framework for communication. Another challenge they mentioned was the different levels of dedication and effort put into the project by the different partners. Some of the partners with the utiliser role were described by several providers as rather passive, "... sometimes stepping in to contribute with specific efforts...". In a way, this mentality was said to affect the rest of the team negatively. If involving any new partners in the future years of the project, a suggestion from several providers as well as one of the researchers was the possibility of involving them only during short-term projects. This may provide a better solution for actors who are only interested in specific areas where they can contribute with expertise, products or services. They also argued that all partners involved in the core decision group of the project need to be highly dedicated and have the desire to collaboratively drive the project forward as a whole. On the other hand, there were also opinions about a partner with the role of a provider taking too great a responsibility and making important decisions without consulting the rest of the team. 
Figure 2 An overview of the themes discussed under the topic 'challenges for sustainable living'

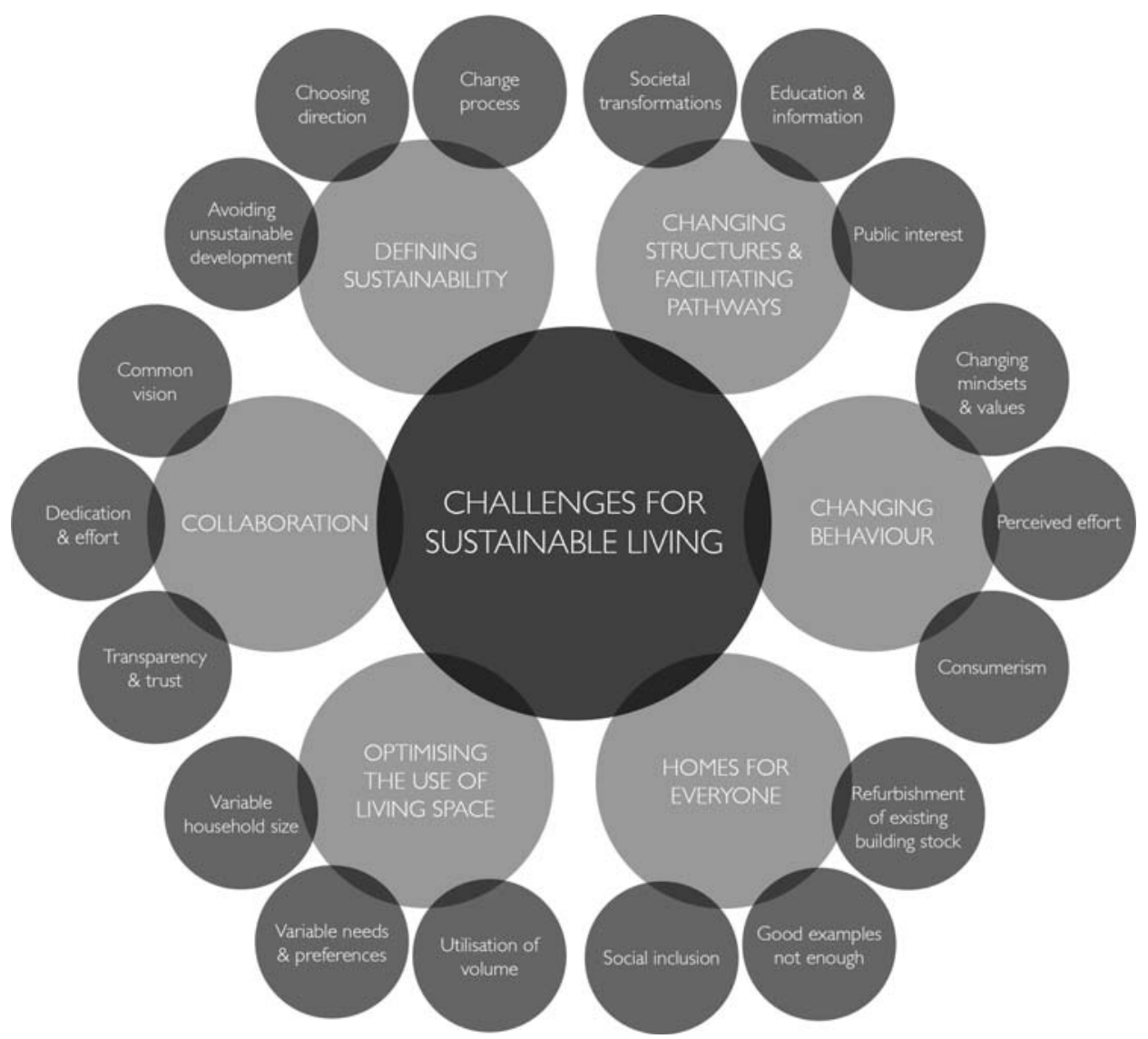

Lack of transparency in the project management processes was brought up as an obstacle by researchers, enablers and providers. A somewhat unclear mandate was explained by one of the researchers as making it difficult to know what it is possible to do and what it is not, but also who you should turn to for different matters. A suggestion by one of the providers was that the university could operate as a neutral bridge, not only between partners and researchers, but in a second step facilitating collaboration between the different partners as well.

\subsection{Potential to accelerate innovations}

Accelerating innovation in the building sector was described as one of the main goals of the Case Living Lab by the actors interviewed. They mainly discussed the opportunities related to the Case Living Lab but also some aspects that could be improved or that needed careful consideration. The different arguments were summarised in a SWOT analysis, shown in Table 4. Although these arguments refer specifically to the Case Living Lab, they can create an awareness of positive as well as negative aspects that may arise in these kinds of projects and so be used as guidelines in the design and utilisation of other Living Labs as well. 
Table 4 SWOT analysis for the potential of the Case Living Lab to accelerate innovations towards sustainable living

\begin{tabular}{|c|c|}
\hline Strengths & Weaknesses \\
\hline $\begin{array}{l}\text { Unique collaboration } \\
\text { - Between academia, industry and society } \\
\text { - International } \\
\text { - Mix of actors from different sectors related } \\
\text { to housing } \\
\text { Solid business system } \\
\text { - Tied partnerships through } 10 \text {-year contracts } \\
\text { Residents } \\
\text { - Interested in sustainability } \\
\text { - Open to new innovations } \\
\text { - Motivated to reduce their environmental } \\
\text { impact } \\
\text { - In their real home context }\end{array}$ & $\begin{array}{l}\text { Limited flexibility of the building } \\
\text { - Compromises in terms of economy and } \\
\text { process } \\
\text { Residents not a representative group of society } \\
\text { Collaboration issues } \\
\text { - Lack of a common vision } \\
\text { - Lack of a solid structure for communication } \\
\text { - Varying levels of dedication and effort }\end{array}$ \\
\hline Opportunities & Threats \\
\hline $\begin{array}{l}\text { Test arena } \\
\text { - 'Risk free' experimentation } \\
\text { - Place for successes and failures } \\
\text { High extent of user involvement and extended } \\
\text { time perspectives in research projects } \\
\text { - Prevention of rebound effects }\end{array}$ & $\begin{array}{l}\text { Missed opportunities } \\
\text { - Not fast enough } \\
\text { - Not brave enough } \\
\text { - Not enough money invested } \\
\text { - Waiting for perfect solutions instead of } \\
\text { trying the best solution available at the time } \\
\text { - Wanting to own instead of sharing }\end{array}$ \\
\hline $\begin{array}{l}\text { Partnership structure } \\
\text { - Quicker market uptake of ideas } \\
\text { - Challenge to innovative and strategic } \\
\text { thinking } \\
\text { - Disseminate knowledge to other projects } \\
\text { - Business generation through continued } \\
\text { collaboration elsewhere } \\
\text { Platform for discussion } \\
\text { - Influence policy } \\
\text { - Challenge the idea of what a home is } \\
\text { Upscaling potential } \\
\text { - In existing building stock } \\
\text { - In new construction } \\
\text { Good example } \\
\text { - Demonstrate the advantages of Living Labs } \\
\text { - Inspiration for other Living Labs and the } \\
\text { building industry }\end{array}$ & $\begin{array}{l}\text { Results not transferred to the market } \\
\text { Ideas and creativity from residents not taken } \\
\text { up } \\
\text { - Inadequate communication channels } \\
\text { Media attention } \\
\text { - Build-up of expectations } \\
\text { - Failure to deliver }\end{array}$ \\
\hline
\end{tabular}


Table 4 SWOT analysis for the potential of the Case Living Lab to accelerate innovations towards sustainable living (continued)

\begin{tabular}{ll}
\hline Strengths & Weaknesses \\
\hline Media attention & \\
- Gain greater impact & \\
- Attract new partners & \\
- Attract students and researchers & \\
\hline
\end{tabular}

\section{Discussion}

This exploratory study has been based on discussions with residents and actors from different sectors involved in the planning, development and utilisation of a new Living Lab research platform. From these discussions, the paper summarises challenges for sustainable living as suggestions of areas that it is relevant for a Sustainability Living Lab to address. It also summarises the strengths, weaknesses, opportunities and threats of a newly completed Case Living Lab as a basis for determining how best to design and utilise a Living Lab focused on sustainable living.

This study presents the potential for Living Labs to act as a platform for experimentation with low associated risks, allowing the actors to step out of conventional patterns in a way that is often not possible to the same extent elsewhere in building projects. Moreover, the study has found potential for Living Labs to create strong collaborations with the exchange of knowledge that may extend individual projects and be applied elsewhere. These are some of the barriers to innovation in the building industry described previously by Beerepoot and Beerepoot (2007), which indicates two areas where Living Labs may open up new possibilities. This study has shown that the success of accelerating innovations through Living Lab projects is dependent on strong collaboration, where the partners have an open exchange of knowledge and dare to challenge their own thinking and business strategies. The main strength of the Case Living Lab is its unique collaboration between academia, industry and society as well as internationally with other universities and organisations. The partnership structure constitutes a mix of actors, who have all signed a 10 -year commitment to the project. This creates a solid business system that ensures continuous replenishment of the shared research funds and increases the potential for quicker market uptake of ideas and innovations generated from the project. A clear communication and clarification of roles between these different actors within the project team is, however, yet to be achieved.

The possibility of acting as a good example of sustainable living was described in the study as one of the opportunities provided by the Case Living Lab. However, in the stakeholder interviews discussions also focused on the fact that good examples alone would not be enough to achieve sustainable living, and that there was a need to take on areas that may seem problematic or difficult as well. New construction only represents a small share of the total building stock, and in order to achieve any further improvements in the overall environmental impact from buildings, there is a need for sustainable innovations that can be implemented in the existing building stock as well. Living Labs have, as discussed in this study, great potential to focus on the development of solutions for refurbishment that can later be scaled up and integrated into existing buildings. 
Another area discussed in the study was the potential of Living Lab research to address user behaviour and daily practices in order to tackle the problems of rebound effects and extravagances, resulting in unexpectedly high consumption levels. A great asset that distinguishes the Case Living Lab from other Living Labs is its permanent residents, enabling a high degree of user involvement in their real home environment. Being mainly students and researchers, they are of course not a representative group of society, thus requiring continued research and testing of solutions elsewhere, as also suggested in the Three-tier model by Keyson et al. (2017). The residents do, however, as discovered in the focus groups and the online survey of this study, possess an interest in sustainability, an openness to new innovations and a motivation to reduce their environmental impact. This makes them, in some aspects, lead users for new sustainable technologies and highly suited to take part in co-creative activities and workshops in the Living Lab.

Finally, since the Case Living Lab is still in such an early phase, this study has not been able to measure any actual success it may have on the acceleration of new sustainable innovations. This will be left for future studies to explore instead.

\section{Conclusions}

Findings from this exploratory study have clearly identified six challenge themes as important to consider for future work in Living Labs, both related to sustainable living and with regards to the potential to speed up innovation in the building sector:

1 changing structures and facilitating pathways

2 changing behaviour

3 homes for everyone

4 optimising the use of living space

5 defining sustainability

6 collaboration.

The greatest potentials for Living Labs that were found in the case study were its ability to offer a platform for discussion as well as experimentation with low associated risks, its user involvement and its ability to bring together different actors with the potential to create strong collaborations that could extend individual projects. Furthermore, this study could confirm the need for the early planning of activities to systematically address the most important challenges and to utilise the Living Lab to its full potential and by more actors. Rather than waiting for perfect solutions to appear, it was found important to also welcome ideas that might offer small benefits in terms of sustainability and make sure that these solutions reached the market at a quicker pace, which could in turn open up opportunities for new research projects.

In agreement with Bergvall-Kåreborn and Ståhlbröst (2009), the Living Lab project team should consist of a mix of market players taking on different roles in the project. All of them should, however, have a strong dedication to share in driving the project forward as a whole. Roles and objectives of the different actors need to be clearly communicated within the team, and the different actors must also have the courage to share their 
knowledge and ideas with each other to enable open innovation and to challenge conventional patterns. As already seen by Schuurman et al. (2016), certain partners with the role of utilisers were found to be better involved during short-term projects only in order to facilitate the communication and establishment of a common vision within the decision group.

It is also recommended that a Living Lab should provide permanent residence for users in order to enable long-term behavioural studies. Living Lab residents should be given the opportunity to take an active part in ongoing research, and a good communication system needs to be established for that purpose to make sure that the ideas and creativity from the residents are taken on board. Furthermore, it needs to be ensured that Living Lab results are intended to do more than simply act as a good example of sustainable living. They also have to focus on solutions that can be implemented in the existing building stock and even to address areas normally outside its technological scope, such as social integration and urban planning. A final conclusion is that a Living Lab should not at any time be seen as a fait accompli, but rather as a process where change has to be established as an essential part.

\section{Future research}

Research studies in the most diverse areas are certainly needed in order to further evaluate the recommendations listed above. Future Living Lab research should adopt a wide focus to also explore new forms of social settings that integrate people of different ages, backgrounds and family arrangements. In the Case Living Lab, it will be interesting to study how the residents' experiences of their living space may change over time. It would also be interesting to extend the options for residents to become more selfsufficient within the Case Living Lab, both in terms of energy and food. From that, the work can continue to explore the boundaries between private and shared spaces as well as resources in order to strive towards long-term solutions for sustainable living that also have positive effects on wellbeing. Finally, future studies in the Case Living Lab should try to evaluate the real impact that it may achieve in terms of accelerating innovation towards sustainable living. In order to explore the extent to which new insights here may contribute to $\mathrm{CO}_{2}$ savings on the one hand and better health on the other, continuous measurements may support an evaluation of the effect on environmental and social gains as well as help to assess the usefulness and potential of the suggested recommendations.

\section{Acknowledgements}

This work has been funded by the Chalmers Areas of Advance Energy and Building Futures. Our acknowledgements also go to Shea Hagy for proofreading. 


\section{References}

Baskerville, R. and Wood-Harper, A.T. (1998) 'Diversity in information systems action research methods', European Journal of Information Systems, Vol. 7, No. 2, pp.90-107.

Beerepoot, N. and Beerepoot, M. (2007) 'Government regulation as an impetus for innovation: Evidence from energy performance regulation in the Dutch residential building sector', Energy Policy, Vol. 35, No. 10, pp.4812-4825.

Bergvall-Kåreborn, B. and Ståhlbröst, A. (2009) 'Living Lab: an open and citizen-centric approach for innovation', International Journal of Innovation and Regional Development, Vol. 1, No. 4, pp.356-370.

Bringezu, S. and Bleischwitz, R. (2009) Sustainable Resource Management: Global Trends, Visions and Policies, Greenleaf Publishing Limited, Sheffield.

Buhl, J. (2014) 'Revisiting rebound effects from material resource use. Indications for Germany considering social heterogeneity', Resources, Vol. 3, No. 1, pp.106-122.

Checkland, P. and Holwell, S. (1998) 'Action research: its nature and validity', Systemic Practice and Action Research, Vol. 11, No. 1, pp.9-21.

CoreLabs (2007) Living Labs Roadmap 2007-2010: Recommendations on Networked Systems for Open User-driven Research, Development and Innovation. Open Document, Luleå University of Technology, Centre for Distance-Spanning Technology, Luleå.

Creswell, J.W. and Clark, V.L.P. (2011) Designing and Conducting Mixed Methods Research, 2nd ed., SAGE Publications, Inc., Thousand Oaks.

Eurostat (2016) Household Composition Statistics [online] http://ec.europa.eu/eurostat/statisticsexplained/index.php/Household_composition_statistics\#Household_size (accessed 17 January 2017).

Geibler, J.V., Erdmann, L., Liedtke, C., Rohn, H., Stabe, M., Berner, S., Leismann, K., Schnalzer, K. and Kennedy, K. (2014) 'Exploring the potential of a german living lab research infrastructure for the development of low resource products and services', Resources, Vol. 3, No. 3, pp.575-598.

Gram-Hanssen, K. (2013) 'Efficient technologies or user behaviour, which is the more important when reducing households' energy consumption?', Energy Efficiency, Vol. 6, No. 3, pp.447-457.

Guerra-Santin, O. (2017) 'Relationship between building technologies, energy performance and occupancy in domestic building', in Keyson, D.V., Guerra-Santin, O. and Lockton, D. (Eds.): Living Labs: Design and Assessment of Sustainable Living, pp.333-344, Springer International Publishing, Cham.

Hargreaves, T. (2011) 'Practice-ing behaviour change: applying social practice theory to pro-environmental behaviour change', Journal of Consumer Culture, Vol. 11, No. 1, pp.79-99.

Hasselkuß, M., Baedeker, C. and Liedtke, C. (2017) 'Social practices as a main focus in Living Lab research', in Keyson, D.V., Guerra-Santin, O. and Lockton, D. (Eds.): Living Labs: Design and Assessment of Sustainable Living, pp.23-34, Springer International Publishing, Cham.

Hertwich, E.G. (2005) 'Consumption and the rebound effect: an industrial ecology perspective', Journal of Industrial Ecology, Vol. 9, Nos. 1-2, pp.85-98.

International Energy Agency (2013) Transition to Sustainable Buildings: Strategies and Opportunities to 2050, OECD/IEA, Paris. 
Janda, K. (2011) 'Buildings don't use energy: people do', Architectural Science Review, Vol. 54, No. 1, pp.15-22.

Johnson, R.B. and Onwuegbuzie, A.J. (2004) 'Mixed methods research: a research paradigm whose time has come', Educational Researcher, Vol. 33, No. 7, pp.14-26.

Kalmykova, Y., Rosado, L. and Patricio, J. (2016) 'Resource consumption drivers and pathways to reduction: economy, policy and lifestyle impact on material flows at the national and urban scale', Journal of Cleaner Production, Vol. 132, pp.70-80.

Keyson, D.V., Morrison, G.M., Baedeker, C. and Liedtke, C. (2017) 'Living Labs to accelerate innovation', in Keyson, D.V., Guerra-Santin, O. and Lockton, D. (Eds.): Living Labs: Design and Assessment of Sustainable Living, pp.55-61, Springer International Publishing.

Leminen, S., Westerlund, M. and Nyström, A. (2012) 'Living labs as open-innovation networks', Technology Innovation Management Review, Vol. 2, No. 9, pp.6-11.

Liedtke, C., Jolanta Welfens, M., Rohn, H. and Nordmann, J. (2012) 'Living lab: user-driven innovation for sustainability', International Journal of Sustainability in Higher Education, Vol. 13, No. 2, pp.106-118.

Lucon, O., Ürge-Vorsatz, D., Zain Ahmed, A., Akbari, H., Bertoldi, P., Cabeza, L.F., Eyre, N., Gadgil, A., Harvey, L.D.D., Jiang, Y., Liphoto, E., Mirasgedis, S., Murakami, S., Parikh, J., Pyke, C. and Vilariño, M.V. (2014) 'Buildings', in Edenhofer, O., Pichs-Madruga, R., Sokona, Y., Farahani, E., Kadner, S., Seyboth, K., Adler, A., Baum, I., Brunner, S., Eickemeier, P., Kriemann, B., Savolainen, J., Schlömer, S., von Stechow, C., Zwickel, T. and Minx, J.C. (Eds.): Climate Change 2014: Mitigation of Climate Change. Contribution of Working Group III to the Fifth Assessment Report of the Intergovernmental Panel on Climate Change, pp.671-738, Cambridge University Press, Cambridge, United Kingdom and New York, NY, USA.

Majcen, D., Itard, L.C.M. and Visscher, H. (2013) 'Theoretical vs. actual energy consumption of labelled dwellings in the Netherlands: discrepancies and policy implications', Energy Policy, Vol. 54, pp.125-136.

Miles, M.B. and Huberman, A.M. (1994) An Expanded Sourcebook: Qualitative Data Analysis, 2nd ed., SAGE Publications, Inc., Thousand Oaks.

Nesti, G. (2017) 'Living labs: a new tool for co-production?', in Bisello, A., Vettorato, D., Stephens, R. and Elisei, P. (Eds.): Smart and Sustainable Planning for Cities and Regions: Results of SSPCR 2015, pp.267-281, Springer International Publishing, Cham.

Pierson, J. and Lievens, B. (2005) 'Configuring living labs for a 'thick' understanding of innovation', Ethnographic Praxis in Industry Conference Proceedings, Vol. 2005, No. 1, pp.114-127.

Pinkse, J. and Dommisse, M. (2009) 'Overcoming barriers to sustainability: an explanation of residential builders' reluctance to adopt clean technologies', Business Strategy and the Environment, Vol. 18, No. 8, pp.515-527.

Rockström, J., Steffen, W., Noone, K. and Scheffer, M. (2009) 'A safe operating space for humanity', Nature, Vol. 461, No. 7263, pp.472-475.

Rosado, L., Kalmykova, Y., Hagy, S., Morrison, G. and Ostermeyer, Y. (2014) 'A living lab co-creation environment exemplifying Factor 10 improvements in a city district', Journal of Urban Regeneration and Renewal, Vol. 8, No. 2, pp.171-185.

Schuurman, D., Baccarne, B., De Marez, L., Veeckman, C. and Ballon, P. (2016) 'Living labs as open innovation systems for knowledge exchange: Solutions for sustainable innovation development', International Journal of Business Innovation and Research, Vol. 10, Nos. 2-3, pp.322-340.

Selvefors, A. (2017) Design Beyond Interventions - Supporting Less Energy-reliant Activities in the Everyday, Chalmers University of Technology, Gothenburg (Dissertation in the Department of Industrial and Materials Science, Division Design \& Human Factors). 
Selvefors, A., Karlsson, I. and Rahe, U. (2015) 'Conflicts in everyday life: the influence of competing goals on domestic energy conservation', Sustainability, Vol. 7, No. 5, pp.5963-5980.

United Nations (2015a) World Population Ageing 2015 (ST/ESA/SER.A/390), Department of Economic and Social Affairs, Population Division.

United Nations (2015b) World Urbanization Prospects: The 2014 Revision, (ST/ESA/SER.A/366), Department of Economic and Social Affairs, Population Division.

\section{Terminology}

\begin{tabular}{ll}
\hline Living Lab & $\begin{array}{l}\text { Open innovation environment for real-life testing and } \\
\text { experimentation where users and actors co-create innovative } \\
\text { products, systems and services }\end{array}$ \\
Sustainability Living Lab & $\begin{array}{l}\text { A Living Lab with an overarching focus on sustainability solutions. } \\
\text { See definition in Section 2.2 }\end{array}$ \\
A recently completed Living Lab that has been the research \\
environment for this study \\
The university, companies and organisations involved in the Case \\
Living Lab project
\end{tabular}

